\title{
Low Carbon Tourism: an Explorative Study on Walking Tours Fostering Responsible Tourism in Delhi
}

\author{
Anu Chandran*, Simran Kashyap ${ }^{\dagger}$ and Bosipoina Golla \\ Suneeth $¥$
}

\begin{abstract}
Sustainable management of destinations strongly advocates for low carbon emission tourism ventures that are eco-friendly. Tourism, however, has a profound potential of sensitisation. Walking Tours are increasingly becoming important for responsible tourism. Delhi is amongst the highly polluted cities of the world though it possesses amazing facets of tourism. While unveiling the relationship between walking tours and responsible tourism, this explorative study underscores the perspectives of the enablers of walking tours in the capital city.
\end{abstract}

Keywords: Walking Tours, Responsible Tourism, Low Carbon Ventures, Sustainable Management, Pollution Control

\section{Introduction}

Tourism is a trillion dollar fortune industry and is growing at a faster pace than international trade. The remarkable growth

\footnotetext{
* Department of Tourism Studies, Pondicherry University, Pondicherry, India; anoos_ind@yahoo.co.in †Freelance Researcher \& Responsible Tourism Intern (Outlook RT); dimsim.k97@gmail.com ‡ Freelance Researcher \& Responsible Tourism Intern (Outlook RT); bgsuneeth@gmail.com
} 
achieved by the industry, world over, has come with certain ramifications. A study, published in Nature Climate Change (2018) estimates that global tourism comprising entertainment, aviation, cruise, and other modes of transportation, accommodation, activities, food consumption, and all the energy and infrastructure required to host visitors produced about 4.5 billion tons of carbon dioxide. Tourism contributes a great deal to the global Gross Domestic Product, and is forecasted to spiral at an annual $4 \%$, thus outwitting many other economic sectors. The global carbon footprint due to tourism has increased from 3.9 to $4.5 \mathrm{GtCO} 2 \mathrm{e}$, four times more than previously estimated, accounting for about $8 \%$ of global greenhouse gas emissions. Transport, shopping, and food are significant contributors. Majority of this footprint is exerted by well-off countries. The rapid surge in tourism demand is countering the decarbonisation initiatives of tourism-related technology. Tourism consumption leads to direct emissions produced by tourism firms, such as hotels, aeroplanes or theme parks, while indirect emissions are the result of direct, indirect and induced suppliers that provide supplements to tourism industries. The concept of low-carbon tourism was formally proposed in the report pertaining to low-carbon travel and tourism industry during the World Economic Forum in May 2009. The trillion-dollar tourism industry is estimated to emit 6.5 billion tonnes of carbon by 2025 , making it one of the fastest-growing sources of the planetwarming gases that the governments are planning to redress. Low carbon tourism is a new form of tourism wooing tourists who wish to have low carbon footprint. Tourism destinations could turn out to be not only places for tourists to visit and stay, but also an interactive sensory experience, which, coupled with low carbon tourism will represent a new way to imbibe higher value for tourists as well as more social, economic, and environmental benefits. Thus, low carbon tourism destinations could be improving competitiveness as well as travel experiences for tourists. A lowcarbon style of life represents the most efficient way to face any environmental problem linked to economic growth. Tourism is related to natural resources; therefore, it is necessary to make it low-carbon. To develop low-carbon tourism, it is necessary to reduce the carbon footprint by creating low-carbon tourism destinations, allocating low-carbon tourist facilities and promoting 
a low-carbon way of tourism consumption (Cai \& Wang, 2010). The essence of low-carbon tourism is to attain a higher quality of tourism experience with less emission in the components of accommodation, transportation, shopping and entertainment. The new energy sources, hotels, restaurants and transportation reduce energy consumption as well as the waste, to achieve a reduction of greenhouse gas emissions such as carbon dioxide. The main requirements of low-carbon tourism are low-carbon transportation, low-carbon consumption, low-carbon accommodation and less travel footprints. The implementation of low-carbon tourism is essential for the protection of environmental resources. To implement low-carbon tourism destinations, it needs to strengthen mechanisms and plans of low-carbon tourism and promote publications on low-carbon awareness. Carbon neutral tourism is a new branch of tourism appealing to those tourists seeking to minimize the carbon footprint of their travel.

Walking, the most common mode of travel, is one of the most popular ways in which tourists can see a destination up close and be active during their visit (Patterson, 2018). Walking tourism allows visitors to directly and deeply experience a destination through their five senses. It also promotes meaningful interactions with local people, nature, and culture. Walking tourism can be developed anywhere that possesses a route with characteristics distinctive to the area - and with relatively low investment costs; when local community resides along a route, as well as other stakeholders, are engaged in its development (Tol, 2018). Walking tourism has the potential to bring a variety of social and economic benefits to the communities. It also promotes the dispersal of tourism demand towards lesser-visited areas and regions, and in off/peak seasons. Walking tours peps-up the intimate/personal contacts of the tourists with the destination attributes. This activity advocates lesser scale and limited resources in terms of the dimensions of tourism development. Walking tours are envisaged in this work as having immense potential to nurture and nourish the ideals of Responsible Tourism (RT). Destination planners and managers promote walking tours such as eco-trails, nature walks, board walks, village walks and heritage walks as giving a fillip to a peaceful state of mind and facilitating relaxed visitation with an easy pace of life. Walking tours devise the offerings and service 
attributes in consonance with the ideals of slow and conscious travel. In that way, the responsibility of the tourists garners robustness towards respecting, investing, and developing local cultures. Walking tours act as a driving force for responsible tourism to fulfil its paramount principle of observing and relishing local norms and practices.

\section{Research Design}

\subsection{Objectives of the Study}

The study has been conducted with the broad objective of gauging how walking tours organised in Delhi create responsible tourists by offering insights on people, places, artefacts, and resources.

The specific objectives encompass:

- To examine the potential of walking tours in promoting the low carbon concept by enabling zero pollution

- To investigate the connection between walking tours and responsible tourism

- To analyse the perspectives of walking tour providers in devising walks as responsible tourism services

\subsection{Area and Scope of the Study}

The study has been conducted in the urban locales of Delhi. Designed as a qualitative work in the exploratory mode, the operations of seven walking tour service providers offering foot walk tours around Delhi for several purposes such as Food Walks, Heritage Walks, Forest Walks, and Cultural Walks were probed. The Participatory Research in Tourism (PRIT) model was carried out to record in-site proceedings along with field observation notes for analysis and drawing inferences

This work is an attempt to navigate the trends of how and why the walk tour providers of Delhi are accentuating their ventures as models to reduce carbon footprints of tourists. This paper also assesses the awareness of tourists as well as their expectations and demands while gearing up for walking tours. 


\subsection{Sampling Method}

Heterogeneous Purposive Sampling Technique and Delphi Technique have been adopted to select the interviewees and conduct Focus Group Interviews and Personal Interviews, keeping in view their nature of operations as well as involvement. The prime focus of choosing the interviewees was to chalk out an overview of their perceptions about the role of their companies initiating changes in the tourism canvas. The experts configured the decision makers of the enterprises. The seven Walking Tour companies subjected to study were Delhi Food Walks, Heritage Walks (Sohail Hashmi), Dilli Meri Jaan, What Happens in Sanjay Van, Open Eyes Project, Food Tours in Delhi, and Delhi Photography Walk.

Simple Random Sampling has been adopted to gather data from the walking participants, viz, tourists.

\subsection{Data Analysis}

Both structured and semi structured interviews were conducted to collect data. Content and thematic analyses have been employed for scrutinising the data and deriving study findings. The outcome of PRIT videos and field-notes were also analysed. This methodology has aided in generating overall ideas about the prevailing scenario and views of promoting walking tours as a tool to promote low carbon tourism. The secondary data has been collected from organisations' literature, journals, and periodicals.

\section{Literature Review}

\subsection{Tourism and Emissions}

The Travel and Tourism (T\&T) sector's current contribution to global greenhouse gas (GHG) emissions is $5 \%$ of the global anthropogenic emissions: Travel and Tourism, excluding aviation, is responsible for about 3\% of GHG emissions. It is estimated that $\mathrm{CO}_{2}$ emissions from tourism (excluding aviation) will grow at $2.5 \%$ per year until 2035 (Carbon Brief, 2018). The Travel and Tourism sector is committed to the cause of emissions reduction to lower its impact on climate change. 


\subsection{Low Carbon Tourism}

Low-carbon tourism is a new way of consumption which is developed following the low-carbon economy (Fu et al., 2008). The concept of low-carbon economy was first proposed in Our Future Energy to create a low-carbon economy by the British in 2003. Extensive economic development, low carbon awareness of inhabitants and absence of low carbon professional talent were the primary factors influencing the growth of the low carbon economy (Liu, 2011).

It is indicated in the Energy White Paper that low-carbon economy is trying to create higher standards of living by less consumption of natural resources, less environmental pollution, and more economic output. Tourists are responsible for global $\mathrm{CO}_{2}$ emissions, accounting for $4.4 \%$, which would continue to increase with an annual rate of 3.2\% from 2005 to 2035 (Peeters, 2010).

\subsection{Practice of Low Carbon Tourism}

Low carbon tourism destinations should adhere to the principle of dynamics, coordinate resources, environment, and human factors (Zhu, 2015). In July, 2009, the first low carbon tour group consisting of 10 Shanghai citizens effectively traveled to the North Pole at their own cost.

Over the years, low-carbon tourism has shown a worldwide boom. Copenhagen, for instance, has taken 50 steps to construct a lowcarbon town, one of which takes complete advantage of Denmark's abundant wind energy. Low-carbon hotels, such as Ton Sai Bay Hotel in Koh Samui, Thailand, have also been introduced in many nations. The notable one is the romantic and luxurious Banyan Tree Resort in Bintan, Indonesia.

Similar to hotels, some carbon-based science museums, such as the California Museum of Science, have emerged. The construction is 70 percent eco-friendly than normal with a covered ceiling of California's indigenous ecological plants, which is not only decorative but also considerably decreases power usage through air conditioning. 


\subsection{Importance of the Development of Low Carbon Tourism Model}

The developing model of low-carbon tourism is to reduce the carbon footprint of tourists and the carbon footprint can be reduced by building low-carbon tourist attractions, allocating low-carbon tourist facilities; promoting a low-carbon way of tourist consumption and nurturing a tourist experience environment of carbon sequestration (Cai \& Wang, 2010).

\subsection{Significance of Walking Tourism}

Walking is one of the most popular ways in which visitors can see a destination in close proximity and be active during their trip. According to Dickinson et al. (2010), slow travel is an emerging conceptual framework which offers an alternative to air and car travel, where people travel to destinations more slowly overland, stay longer and travel less. Walking tours is a method of promoting low carbon tourism and is also a propagator of slow and conscious travel. It is highlighted by many a research work that walking tourism enables tourists to experience a destination through their five senses in a deeper vein. It also fosters significant relationships with indigenous people, with natural ecstasies, and with cultural expressions. Walking tourism can be designed wherever a path is located with area-specific features-and comparatively low cost of investment. Walking tourism has the power to bring a spate of social and economic advantages to the societies when host community members and tourists walk along a path, as well as when other stakeholders are involved in its growth. It also provides impetus to the dispersal of tourism demand in and off/peak seasons towards less-visited areas and regions.

\subsection{Relevance of Walking Tourism}

Tuan (1974) posited that walking involves a multiple sensory interaction with any location, serving to develop a more complete sense of the place. Walking tourism is now one of destinations' most common modes. According to UNWTO Report on Regional Development 2019, walking tour enables more engagement with local individuals, nature, and culture for visitors. It also meets the need for physical and safe operations of latest travellers during their journey. Gentry (2007) emphasised that walking promotes a 
greater engagement with place; motorized tours may limit the engagement through time and sightlines. Walking tourism can be designed anywhere with comparatively meagre investments as a sustainable tourism offering. If created and managed with exactitude, it can usher in social and fiscal advantages to inhabitants and communities. Because walking is appealing not only for tourists but also for residents in order to preserve and improve their well-being, a destination can also consider it a means of its welfare strategy and promote inclusion of tourists and residents.

\subsection{Advantages of Walking Tourism}

Walking Tours are relatively easy to develop as it requires relatively little investment which does not even require special resources. It has profound market potentiality as it complements other tourism resources. Walking tours can be crafted as a sustainable tourism product, if developed and managed properly with high potential to create economic benefits to the host population. Walking tours also has high potential to promote residents' wellbeing and welfare (UNWTO - Walking Tourism, 2019).

\subsection{Factors to be considered in Walking Tourism Development}

Albeit, walking tourism can be developed anywhere, a destination needs to think about its potential depending on its objectives and target segments from casual walkers to serious hikers (Walking Tourism - Promoting Regional Development, 2019).

In sync with the above, during the actual development phase, the key elements to be considered are the following:

- Route characteristics (attractiveness, safety, level of difficulty, access);

- Necessary facilities (signage, toilets, benches, etc.);

- Maintenance system;

- Economic opportunities (accommodation, transport, retails, cultural programmes, links to gastronomy and wine tourism, etc.) and

- Marketing and commercialisation 
Walking is the best way to explore and experience the uniqueness of a place in a carbon friendly way and therefore it should be further developed as a model (UNWTO Report, 2019).

\section{Case Studies}

\subsection{Delhi Food Walks}

Delhi Food Walks conduct food expeditions to enable tourists to relish the food culture of Delhi and interact with fellow food enthusiasts. It began in 2011 to act as a stronghold of Delhi food culture and is one of the most popular companies conducting the walk.

\subsection{Open Eyes Project}

Open Eyes Project is a company that organises sustainable trips in India. They have been working since 2011 to make vacations sustainable for everyone by conducting walk tours, especially with women guides.

\subsection{Heritage Walks - Sohail Hashmi}

Sohail Hashmi is a historian who conducts architectural walk throughout Delhi for the company of India Heritage walks and Mehrauli Walks.

\subsection{Dilli Meri Jaan}

Tourists are enticed to experience the invigorating city of Delhi through their senses. Every weekend, tourists are induced to vanish into one of the many green spots of the city and listen to the birds, butterflies, and bees. Two hours of green, oxygen-filled air helps the tourists get back to the city with renewed vigour, heightened awareness, and a sense of pride.

\subsubsection{What Happens in Sanjay Van}

What Happens in Sanjay Van is an art project that strives at understanding and unveiling some uncomfortable realities of the dying state of Sanjay Van (an urban forest in the heart of the metro of New Delhi) and a celebration of the sparkle that this forest sustains against all odds. 


\subsubsection{Food Tour in Delhi}

Delhi Food Tour is the oldest authentic food walk company in India, providing various authentic Food Travel walks at several parts of Delhi and Jaipur.

\subsubsection{Delhi Photography Walk}

Delhi Photography Club, a platform built for photography beginners, amateurs, enthusiasts and hobbyists, was built on an idea to connect every photography enthusiast by a common thread through walks. They inspire and invent new ideas in this visual art. Furthermore, DPW inculcates and motivates the art of photography in people through their varied walks. They are pioneers of starting Heritage Photowalks and organise four photowalks every month for the photo enthusiasts.

\section{Results and Analysis}

Interviews with Service Providers and their Customers (Coded Responses)

\subsection{Food Tour in Delhi}

Tourists are offered ample opportunities to explore new places with stories and have an interface with food vendors. All the places are carefully chosen on the basis of hygiene, ingredients used and history behind the food. The foodie guests are quite passionate about the walks. Tourists are briefed on low carbon activities and they are advised not to waste food. Tourists' posses global knowledge, know their city well and are curious enough to know about other cultures. The organisation motivates tourists to use eco-friendly products. Thrust is laid on the awareness campaigns. To understand the root level culture, walking tours is the best.

\subsection{Dilli Meri Jaan}

The focus is on green spots of Delhi and research on its flora and fauna. Spotlight is also turned on into historical aspects. The itineraries are an interesting mix of trees, birds, metro, and theme parks. Feedback is taken from walkers at every destination. Kids evince a lot of interest in walking activities. They are at the forefront of green initiatives. There are Standard Operating 
Procedures for the walk tours. Walkers also interact and share their ideas. Guides are inducted after thorough screening. They are equipped to impart environment education. Youth leadership is an important component of Dilli Meri Jaan Walks. Utmost care is taken that the walk outcomes make sense to the tourists. Over the years, eco-consciousness of the walkers has gone up by miles. Sanjay Van and Jahanpanah walk are very popular. Dilli Meri Jaan has been established to promote responsible living through tourism. Yet another aim of the organisation is to make the tourists realise the fun of being outdoors, communicating with nature and using public transport. Through the walks and posts on social media platforms, the organisation helps people become more aware of every action they indulge in, how it impacts the future generation. Walkers are also urged to pick up trash in forest and city limits. They are also motivated to eat fresh foods/coconut water/snacks available locally using their own cutlery. Dilli Meri Jaan believes that responsible tourism is a result of higher awareness of actions. The architectural feats of bygone rulers are pointed out during the walks along with the speciality of birds.

\subsection{Delhi Photography Walk}

This walk tour program is offered by the Delhi Photography Club. It is a creative journey which creates space for photography enthusiasts. They devote time intensively at the destinations and also in line with slow and conscious travel which enables them to take more meaningful pictures. The paradoxical aspects related to the preservation of urban environs are portrayed through the walk tours as well as photography. One distinct walk tour itinerary is the heritage photo walk which is a blend of admiration of heritage, learning, photography and fun. The basic idea of heritage photo walks is to provide participants with the opportunity to appreciate and capture with their cameras the rich heritage and legacy of Delhi which is priceless. As a group, the photography buffs are taken to places that possess spectacular photo-ops. Several monuments such as Red Fort, Safdarjung tomb, Hazrat Nizammudin, Lodhi Garden and Humayun Tomb are usually covered. Photo walks are experiential in character and promote low carbon tourism. Sharing of photo walks furthers the cause of low carbon tourism ventures. The upkeep of tourists' spots in Delhi i.e., 
the physical evidence is usually given accent. Zero waste tourism campaign is gaining traction owing to photo walks. Tourists categorically stated that photo walks to Jama Masjid and Feroz Shah Kotla during Ramadan certainly promotes responsible pilgrim tourism. Heritage photo walk engages a trained guide who brings the history alive with anecdotes, narratives, and stories. Heritage tourists tend to opine that the form of tourism also entails culture, environment, and traditions that are inherited. The clientele comprises foreign nationals, BSF, British Council, etc. Strictly, no vehicles are used for travel within the city. DPC is working on a unique project in Rajasthan for converting a village into an artistic retreat. The name is Mandawa Art Village. The initiative is to promote and strengthen the local art and culture. Tourist visiting Mandawa relish the murals and wall frescos. DPC attempts to brand the art forms as tools for change and development which is in consonance with the paradigms of responsible tourism.

\subsection{What Happens in Sanjay Van}

This organisation is committed to environmental protection. Pioneering the concept of walking in the moonlight of Delhi; it enables individuals to come into contact with nature without any kind of technological mediation. Even torches are not allowed. There are chance encounters with hares, jackals, neelgais and fireflies amidst the silence and moonlight streaming through the canopy of trees. The foraging walks have become quite popular with foreign clients. Lodhi Gardens is the favourite location for the programme. Edible flowers such as nasturtium, begonia, dianthus, marigolds etc, are cultivated and collected. Tourists get chances to explore the garden's herb beds and plantations. The scavenging walks underpins utilisation of discarded junk to bring about an awareness of how easy it is to shrink carbon footprints by going local and by reducing trash.

\subsection{Heritage Walks (Sohail Hashmi)}

The immersive heritage walks conducted around Delhi by renowned academic, historian and filmmaker Sohail Hashmi explores various streets and by-lanes. There are exclusive tours for the kids. They are taken to places like Tughlaqabad where children 
learn about the rock formations. Children can walk on the ramparts, run down the steps in a baoli and see creatures they have never seen - a mongoose or a nilgai or something as simple and beautiful as a pupa turning into a butterfly. The walks are organised in Old Delhi.

\subsection{Open Eyes Project}

The organisation is working to explore and identify the requirements of societies and visitors to implement accountable trips. The latest project 'Wellness Retreat' employs blind people as massage therapists. The focus is also on inclusive tourism for women, particularly visually impaired women. Accountable tours are the hallmark project. Furthermore, the Spice Girls Walk Tour of Old Delhi offers a deep dive into the local culture of India's bustling capital city. On this culturally vibrant walking tour, tourists will discover a mindboggling variety of foods, spices, and speciality dishes from local women guides. The main aim of the project is to contribute to the reduction of carbon footprints of tourists as well as empowering women.

\subsection{Delhi Food Walks}

Walking tour programmes of Delhi Food Walks allows walkers to connect with the local community and places. It helps the tourist to experience the culture of the place in a way that their carbon footprint is reduced. Relishing the destination with food in a carbon-friendly way is the main motive of DFW.

\section{Inferences and Discussions}

Thematic analysis has been carried out and the relationships between the variables interpreted and presented below.

\subsection{USPs of Walking Tours}

Food walk is one of the most popular forms of walking tours which are mostly preferred by foreign tourists. Heritage walk is also highly rated by tourists as it helps them to experience the diverse culture. Photography walk is a recent trend that is gaining coinage. 


\subsection{Challenges of Walking Tours}

The main challenge of the walking tours is serving to the different needs of the travellers as everyone would have distinctive and varied expectations. Another challenge that the walking tour providers mostly face is of time management as some walkers are swift whereas some engage in leisure walking. Maintaining standard rates for the walks is also challenging. To employ guides having sound expertise in the field and possessing appropriate soft skills is an issue to be handled meticulously.

\subsection{Opportunities for Walking Tours}

The outcome of the study established the fact that there is a steady increase in tourists opting for walking tours. Consequently, there will be tremendous opportunities for the sector. Tours such as moonlight walks are in great demand. Interactive walking tours with the local community helps tourists have a better experience.

\subsection{Tourists' Expectations}

The expectations of tourists from walk tour programme vary according to the theme of the tours. For photography walks, tourists prefer longer walk duration and bright summer sun for better clicks whereas for heritage and cultural walks tourists ideally prefer three to four heritage sites. As regards ecological walks, tourists prefer engagements with natural resources such as foraging or spotting birds. Price stability is one aspect in which the tourists are very particular.

\subsection{Walk Tours for Promotion of low carbon tourism}

Walking tours are a major low investment way to promote sustainable development of an area. Walking tours do away with vehicular movements and promotes sensible and sensitive conduct at the destinations. This helps in reducing the carbon footprints and helps the conservation of destination resources while giving the tourist experiential delight. Walking Tours are responsible as they include eco- friendly practices that acknowledge local culture. 


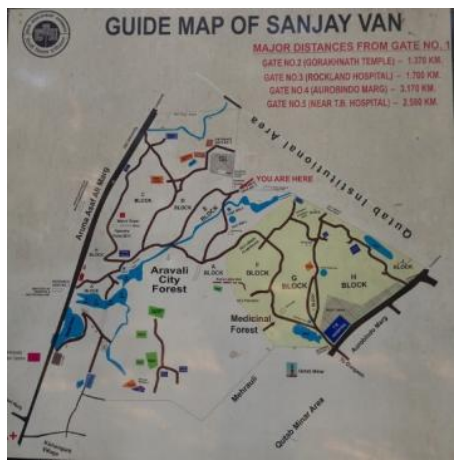

Fig.1: Eco-Walk Mapping of Sanjay Van

\section{LODI GARDEN}

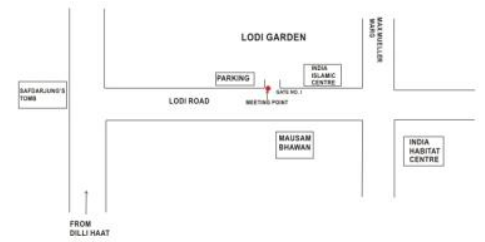

Fig.2: India Heritage Walk - Route Plan

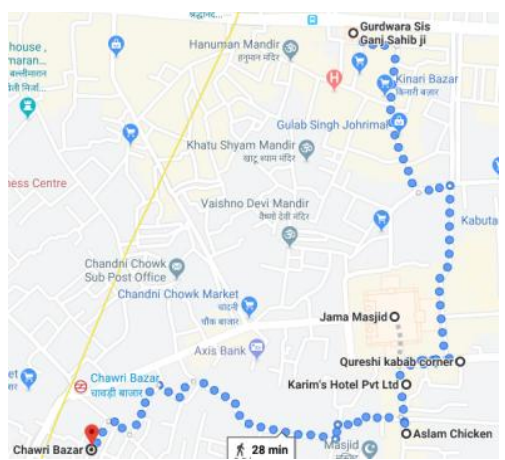

Fig.3: Food Walk Tour of Delhi Food Walk at Old Delhi adapted from Google Map 


\section{Major Findings}

The major findings of this work are depicted as follows. Walking tours lay stress on eco-friendly conduct of tourists. Due thrust is accorded to low-carbon activities. Avoidance of vehicles for operating tours contributes a great deal to curbing pollution. The operators of Delhi are very sensitive towards mitigating emissions and therefore strongly advocates for innovative and theme-based walking tours. The reciprocation from the tourists is also astounding as they prefer to pro-actively take part in the various interesting walk tours. Tourists are on the lookout for the experiential dimensions of the walk tours. Majority of the tourists expressed an inclination to relish the local flavours of the places which configure cultural manifests, cuisine, shopping, and activities. Dedicated walking lanes for the theme tours were preferred by a sizeable number of tourists. This would allow them to walk freely without being wary of the traffic.

- Most of the popular walk tours last for not more than 3 hours as it is what the tourists prefer.

- Every walk tour has a Unique Selling Point (USP) where interaction with local community was mostly included.

- The price of every walk tour is inclusive of all the services that would be offered during the tour such as the food to be consumed or entry tickets.

- Since walk tours are intangible services, many a walking tour company provide their own badge or care package to the tourists after the walk's end.

- Proper instruction of, if special requirements needed, is informed to the tourists much before the walk tour starts

- Discount rates are given to tourists if they book in larger groups which are encouraging more tourists to avail.

- Some walking tour companies also include cycling trails if tourists want to take longer trails. 
- There are walking tour companies such as Woman Eye Project which are engaging women guides for the walk of women only groups, thus empowering women.

- Foraging is promoted by What Happens in Sanjay Van. Thus, it helps tourists to experience more than walking and they can also contribute more to the environment.

\section{Suggestions}

- The duration of walking tours must be flexible and in line with the themes and programmes.

- A concrete research of clients' expectations is a dire necessity before the commencement of the walking tours. This serves to cater to the needs of diverse customers.

- The clients of walking tours generally tend to seek new facts about the destination charms they will be partaking with, say food or heritage walk. Thorough knowledge of offerings of destinations is required to woo the tourists.

- The tour guides are the ones who will interact with the tourists during the walks and therefore they should have proper training over soft skills and destination knowledge.

- Walking tour companies should provide Walking Festivals and amusement activities where all the companies could come and collaborate to make it easier for the tourists to examine all kinds of tours available in a common platform

- Since walk tours help reduce the carbon footprint of travellers they should be well informed about this after the tour ends so that they can act more responsibly during their next tour.

\section{Conclusion}

Walking tours offer many tangible and intangible benefits to tourists as indicated in the study. As a common non-polluting mode of travel, it is one of the popular ways in which tourists can enjoy a destination up-close and remain very dynamic. In Delhi, 
the sensitisation campaigns by way of walking tours, as regards eco-friendly conduct of tourists are garnering momentum. Walking tours provides the leeway to the tourists to directly and deeply experience destination attributes through their five senses. It also promotes slow and conscious travel galvanising meaningful interactions with local people, nature and culture. As a mode to promote low carbon tourism, walks should be promoted more innovatively and interestingly. On the responsible tourism plane, walking tours in Delhi are bound to engender respect between tourists and hosts. In Delhi, which is smouldering due to high pollution levels, walking tours are found to be soothing and offers a pleasing experience.

\section{References}

Cai, M., \& Wang, Y.M. (2010). Low-carbon tourism: a new mode of tourism development. Tourism Tribune, 1(5), pp.13-17.

Cape Town Declaration on Responsible Tourism - Responsible Tourism Partnership. (2019). Retrieved 12 July 2019, from https:// responsibletourismpartnership.org/cape-town-declaration-onresponsible-tourism

Carbon Brief. (2019). Tourism responsible for $8 \%$ of global greenhouse gas emissions, study finds. Retrieved 9 December 2019, from https://www.carbonbrief.org/tourism-responsible-for-8-of-globalgreenhouse-gas-emissions-study-finds

Dickinson, J., \& Lumsdon, L. (2010). Slow Travel and Tourism. London: Routledge, https://doi.org/10.4324/9781849776493

Fu, Y., Ma, Y.H., Liu, Y.J., \& Niu, W.Y. (2008). Development patterns of low carbon economy. China Population Resources and Environment, 3, 14-19.

Gentry, G.W. (2007). Walking with the dead: The place of ghost walk tourism in Savannah, Georgia. Southeastern Geographer, 47(2), 222-238.

Liu, C., \& Zhao, T. (2011). Research on development of China's lowcarbon economy in 2020. China Population, Resources and Environment 21(7), 77-83.

Meng, C., \& Yuming, W. (2010). Low-carbon Tourism: A New Mode of Tourism Development. Tourism Tribune, (1), 13-17.

Peeters, P., \& Dubois, G. (2010). Tourism travel under climate change mitigation constraints. Journal Of Transport Geography, 18(3), 447-457.

Tol, R. (2018). The economic impacts of climate change. Review of Environmental Economics and Policy, 12(1), 4-25. 
World Tourism Organization. (2019). Walking Tourism-Promoting Regional Development. UNWTO, Madrid, DOI: https:// doi.org/ 10.18111/9789284420346 accessed on 9.7.2019

Yun, F., Yong-huan, M., Yi-jun, L., \& Wen-yuan, N. (2008). Development Patterns of Low Carbon Economy. China Population Resources And Environment, (3), 14-19.

Zhao, L., \& Tao, Z. (2011). Research on Development of China's LowCarbon Economy in 2020. China Population Resources and Environment, (7), 73-79. 